\title{
Presencia en las sucesivas ediciones del diccionario académico de los tecnicismos de la pesca extraídos de las Ordenanzas de Sevilla
}

\author{
STEFAN RUHSTALLER \\ Universidad Pablo de Olavide, Sevilla
}

\section{INTRODUCCIÓN}

Una buena parte del léxico no perteneciente a la lengua común acopiado en el $D R A E$ figuraba ya en el Diccionario de Autoridades $(D A)$. Ahí entró mayoritariamente a través de las citas incluidas sistemáticamente en los artículos lexicográficos, citas procedentes no sólo de textos literarios, sino también de otra índole, como eruditos o legales. Una fuente de léxico marcado de este último tipo la constituyen las Ordenanzas de Sevilla (OSe.), recopilación impresa en 1527 de textos manuscritos anteriores que fijaban las normas de trabajo de los distintos gremios. Los 89 registros de $D A$ que contienen citas de este texto son casi todos rarezas léxicas -tecnicismos, arcaísmos, dialectalismos, o todo a la vez-, y la mayoría no habría podido ser documentada de no haber sido explotado el texto sevillano por los lexicógrafos. Su explicación lexicográfica fue muchas veces extremadamente difícil debido a la escasez de información de que disponían los académicos. En un trabajo reciente (Ruhstaller 2004) he analizado este conjunto léxico en $D A$; el presente lo dedicaré al estudio de algunas de las voces en cuestión en la lexicografía académica posterior.

2. Los TECNICISMOS ARCAICOS DE LA PESCA PROCEDENTES DE LAS ORDENANZAS EN EL $D A$ y EL $D R A E$

2.1. Los primeros académicos dedicaron un artículo a la voz almancebe que aparece tres veces en las OSe. (cito los pasajes en 2.3). Ni siquiera los lexicólogos modernos han podido localizar más documentación de la voz, y el contexto en que figura en las $O S e$. es insuficiente para determinar con exactitud el significado de este término téc- 
nico de la pesca (según señala expresamente el $D C E C H, s . v$.). Desde luego, no resulta plausible-pues las terminologías profesionales se caracterizan precisamente por la sutileza con que deslindan los conceptos específicos de su ámbito del saber- que poseyera simultáneamente las tres acepciones que -por conceder demasiada credibilidad al $D R A E$, según veremos- distingue el $D H$.: «lugar en el río Guadalquivir para cierto tipo de pesquería», «cierto tipo de red usada en el río Guadalquivir» y «cierto barco pequeño donde tenía lugar esa pesca» (Ruhstaller 2004: 119). Tal vez sirva de orientación para reconstruir el significado el étimo hispanoárabe; según la hipótesis del DCECH (s. v.), «no hay duda de que mánsib significaría el 'lugar donde se tendían las redes o los lazos'».

A pesar de lo poco conocido que resulta el término almancebe, la Academia lo ha mantenido ininterrumpidamente en sus ediciones desde 1726 a 2001, incluso en su diccionario manual. Lo adoptaron mecánicamente también la práctica totalidad de los diccionarios posteriores (incluidos los actuales, como Vox y Larousse). Los creadores del $D A$ creyeron poder establecer un significado inverosímilmente amplio para este término técnico: «el conjunto de redes, barco, y demás aparéjos para cierto género de pesquería y lance de pescar echado en el rio Guadalquivir en las cercanías de Sevilla por sus pescadóres». En la segunda edición, sin duda tras una nueva evaluación de la fuente, se restringió a «el barco preparado para cierto género de pesquería que se hacia en el rio Guadalquivir cerca de Sevilla». ${ }^{1}$ Otro cambio radical -este originado con toda probabilidad por la etimología- se produce en el DRAE-1884, cuando -sin alcanzarse la precisión semántica deseable en un diccionario de las pretensiones del $D R A E$ - la voz se define como «especie de red que se usaba en el Guadalquivir». Posteriormente -en el $D R A E$-2001- ya sólo se añade una puntualización carente de interés: «especie de red que se usaba en el Guadalquivir, río de España».

Así, también otros elementos de la microestructura se ven modificados en las sucesivas ediciones: si los primeros académicos no se aventuraron a formular hipótesis etimológica alguna, en 1884 la voz se derivaría del ár. al-monceb «red tendida». En 1970 se da preferencia a al-mansab «el lugar donde se echan las redes», mientras que en la última versión se postula un ár. hisp. almansába «banco». Pero lo más llamativo es la descripción del uso de este término documentado exclusivamente en el texto de 1527: mientras en la primera edición del $D A$ todavía se aludía al sector de hablantes al que pertenecía la voz («...por sus pescadores») y se advertía expresamente que se trataba de una «voz antiquada», desde el $D A-1770$ se restringía diacrónicamente mediante la marca «ant[iq].» combinada con el empleo del imperfecto dentro de la definición; desde el $D R A E-1884$ es ya únicamente este tiempo verbal el que señala la falta de uso en la lengua moderna. Algún diccionario actual

1 Paralelamente a la definición española se modifica la latina: «omnia instrumenta piscatui apta» en la primera edición del $D A$ se sustituye por «piscatoria cymba» en la segunda. 
incluso hace creer que el término aún conserva vitalidad: «red de pesca que se usa en el Guadalquivir» (Larousse).

2.2. La voz almatrero, «el que pesca con sabogales», está, como determinó Corominas, estrechamente relacionada con almatroque, ${ }^{2}$ nombre de una red de pescar fina similar al sabogal que utilizaban los pescadores del Guadalquivir, descrita pormenorizadamente por Sáñez Reguart en su Diccionario histórico de las artes de la pesca nacional (1791). Tanto almatroque como almatrero son voces documentadas en una sola fuente -el primero en el diccionario de Sáñez, ${ }^{3}$ el segundo en las $O S e .-$, y tendrían un uso limitado exclusivamente al lenguaje de los pescadores del Guadalquivir de siglos pasados.

El tecnicismo antiguo figura en la nomenclatura del diccionario académico -incluida la del manual- de 1726 a 1989, pero falta en las eds. de 1992 y 2001. La definición del $D A$, «el que usa pescar con un género de redes, que llaman sabogáles, porque con ellas cogen unos peces que se llaman sabógas», se reformula en 1770 como «el que pesca con unas redes, llamadas sabogales, porque con ellas se cogen las sabogas», redacción que se mantiene más de un siglo (en el DRAE-1852 se elimina únicamente la coma tras «redes»). En el $D R A E-1884$, sin embargo, se produce un cambio total, estableciéndose en la propia definición una relación con el término del que etimológicamente deriva la voz: «el que tenía por oficio pescar con almatroque».

La definición latina ofrecida en $D A$-«piscator salparum, aut thrissarum»- se abrevia en el DRAE-1852 en «piscator salparum». Ninguna de las ediciones se pronuncia sobre la etimología. En lo que se refiere al uso del término, llama la atención la falta total de marcas restrictivas; únicamente a partir del $D R A E-1884$ se señala implícitamente una limitación cronológica («El que tenía por oficio...»).

2.3. En un contexto casi idéntico al de almatrero figura en las $O S e$. (159 y 160) una voz de aspecto sospechosamente similar:

Otrosi, que ningun almatrero de sabogales, de aqui adelante no tomen almancebe, fasta mediado el mes de Febrero: y que si se fallaren más barcos de vno, que echen suertes entre ellos a quien cupieren, y no aya otra diferencia sobrello.

2 Corominas ofrece una explicación etimológica de esta forma, que naturalmente no puede derivarse directamente de almatroque. Ahora bien, tampoco sería descabellado pensar que almatrero fuera una de las no demasiado raras erratas achacables al impresor de las $O S e$., y que el tecnicismo realmente fuese *almatroquero ( $c f$. los casos de almacaero, aljarfe y alcabala; también Ruhstaller 2004: 115).

3 Pues las demás obras, todas lexicográficas, que según el $D H$ la recogen, obviamente no hacen sino reproducir el mismo dato. 
Otrosi, que ningun almacaero, no sea osado de empachar mas de vn almancebe: so pena de trezientos marauedis, y que ninguno no pueda echar sino vn almancebe, desde la huerta de barriga, que es a la Puebla, fasta la peña, so la dicha pena.

Se trata del único testimonio de la forma - pues los demás diccionarios no hacen sino copiar mecánicamente el dato de $D A-$, y dado su extraño aspecto Dozy la consideró lectura corrompida de *almancebero (derivado de la voz almancebe, tratada arriba); pero en vista de la similitud de los contextos en que aparecen estos hápax es evidente que lo es de almatrero (posibilidad que ya consideró Corominas, $D C E C H$, s. v. almancebe). No cabe duda alguna de que el impresor de las OSe. -lógicamente desconocedor absoluto de la jerga profesional de tradición puramente oral de los pescadores del Guadalquivir cuyas normas laborales debía copiar de un manuscrito del siglo anterior- reprodujo como almacaero lo que en el manuscrito era almatrero.

Es, pues, más que probable que almacaero sea una voz fantasma, por lo que la decisión de suprimir el registro en 1992 fue un acierto (antes, no obstante, se había acogido incluso en el diccionario manual). Pero ya en la definición de 1726 se percibe la inseguridad de los lexicógrafos ante el término: «el que tiene por exercicio un género de pesca, que se hace con barco en el rio de Sevilla: y porque llaman Almancébes à los barcos empleádos en esta pesca, llaman Almacaeros à los que la usan, para distinguirlos de otras diferéncias de Pescadóres». En la segunda edición de $D A$ esta descripción semántica se reduce a «el que tiene por oficio un género de pesca que se hace con barco en el rio de Sevilla». En el $D R A E-1884$, tras una nueva evaluación del texto de las $O S e$., se elimina la imprecisión patente en la expresión «un género de pesca», y se introduce la referencia al almancebe (término, no obstante, como vimos, no menos imperfectamente conocido): «el que tenía por oficio pescar con almancebe».

La definición latina se mantiene de 1726 a 1803 como «qui ex cymbula piscatur, piscator [h]orarius», y se abrevia en el $D R A E-1817$ : «qui ex cymbula piscatur». Ninguna edición ofrece etimología. En cuanto a la descripción del uso, resulta chocante la ausencia total de marcas; sólo implícitamente se señala el arcaísmo a partir del $D R A E$-1869 mediante el uso del imperfecto en la definición («el que tenia por oficio...»). Al menos, el $D A$ alude vagamente al carácter técnico de la voz, a través de la tercera persona de plural y la referencia a las necesidades de distinción semántica más sutil de los usuarios de tecnolectos («llaman Almancébes à [...] para distinguirlos de otras diferéncias...»).

2.4. Al igual que almacaero, también alcabala, definido en el $D A$ («Se llama assi el seno, ò centro de las redes de pescar, que por otro nombre se llama Xabéga»), es una voz fantasma que entró en el diccionario académico a partir de una forma mal reproducida por el impresor de 1527; en el ms. de las ordenanzas de cordoneros de redes 
que fue la base de la versión impresa figura realmente alcanela ${ }^{4}$ denominación de red bien documentada. Esta voz inexistente ${ }^{5}$ persistió en el diccionario académico hasta 1984, si bien al menos el diccionario manual había renunciado a su inclusión. En una primera etapa (de 1726 a 1869) la forma se trataba como acepción de alcabala 'tributo', mientras que en una segunda (a partir del DRAE-1884) los términos se han considerado homónimos y han recibido artículos independientes.

La citada definición de la primera edición del $D A$ es modificada sustancialmente en la segunda, donde -sin duda tras interpretar de nuevo el contexto que ofrece la fuente- se explica el término como «especie de red para pescar: lo mismo que xábega». ${ }^{6}$ Desde el $D R A E-1884$ la explicación semántica se limita a la indicación del supuesto sinónimo jábega. A excepción de la primera edición del $D A$-donde se traduce «Interior retis piscatorii sinus»)- se prescinde de la habitual versión latina de la definición. Igualmente se omite la información etimológica hasta el $D R A E-1884$; el étimo ár. alquebol establecido en esta fecha se mantiene hasta la supresión de la voz en el $D R A E$-1984. Sorprendentemente parca es, de nuevo, la caracterización del uso de este (en realidad inexistente) tecnicismo arcaico local: la única marca que lo acompaña es «ant.» a partir del DRAE-1803.

2.5. Tres veces aparece en las OSe. la forma aljarfa, y una vez una variante aljarfe. La autenticidad de la primera está fuera de duda no sólo por su recurrencia en el texto, sino también por el testimonio de Sáñez Reguart, quien la recogió, sin duda directamente de boca de los pescadores del Guadalquivir, como arfa. ${ }^{7}$ La segunda forma, aljarfe, en cambio, ha de ser una errata más ${ }^{8}$ achacable al impresor de las OSe., desconocedor de la terminología de los pescadores locales. A pesar de ello, el $D A$ registra ambas formas, si bien bajo un único lema: ${ }^{9}$ aljarfa, o aljarfe. Sólo a partir del DRAE1884 se elimina esta anomalía al dedicarse entradas diferentes a cada forma (si bien desde aljarfe se remite directamente a aljarfa). Curiosamente, la edición más moderna vuelve al doble lema inicial: aljarfa o aljarfe. La «oficialización», a través de su registro en el $D A$, de la errata aljarfe hizo que se extendiera ampliamente por los diccionarios del español: como se desprende de los materiales acopiados en el $D H$, la

4 Véase García Cornejo (2001: 232) y Ruhstaller (2004: 111).

5 El DCECH (s. v. alcabala) reproduce, con reservas, la interpretación del término de Dozy, pero destaca que, para llegar a una conclusión segura, «hacen falta más ejs.» de la voz.

6 Terreros mantiene la definición de la primera edición del $D A$.

7 La forma oral sería la aharfa [la:hárfa] - $c f$. pronunciaciones populares andaluzas del tipo [aharáfe] 'Aljarafe', [aherífe] 'aljerife' (vid. infra)-; Sáñez la interpretaría como plural las arfas, reconstruyendo un singular arfa.

${ }_{8}$ Facilitada por el arcaico uso del artículo el ante sustantivo femenino que comienza por $a$ - átona (el aljarfa).

9 Hay otros casos de doble lema en el DA, especialmente diminutivos (Ruhstaller 2001: 207, n. 5). 
reproducen prácticamente todos los diccionarios tanto especializados como no especializados posteriores; Sáñez Reguart, al escribir erróneamente aljarme, incluso crea un nuevo fantasma que se propaga a otros diccionarios posteriores (hasta el $\mathrm{DH}$ lo recoge sin observación alguna).

En cuanto al aspecto semántico, el $D A$ ofrece en un solo enunciado definicional dos significados alternativos: «Es una red espesa alquitranada ò parte de la red mas espesa que los demás, que tambien llaman copo». Esta fórmula se repite hasta el $D R A E-1791 ;{ }^{10}$ en el DRAE-1803 la Academia, no obstante, se decanta ya exclusivamente por el valor «[lo mismo que] COPO, por la parte más espesa de la red de pescar», definición que se simplifica en el DRAE-1884 remitiendo únicamente al sinónimo copo. Ya en la segunda edición del $D A$, en cambio, se corrige la imprecisa definición latina: «retis quoddam genus, Arabibus usitatum» se sustituye por «rete naphtha illinitum, vel retis spissior pars» (al tratarse de un término de los pescadores sevillanos del siglo XVI, el objeto designado lógicamente era utilizado no sólo por los árabes).

La inadecuada traducción latina del $D A$ se debió, obviamente, a la etimología de la voz; en efecto, los fundadores de la Academia señalaron: «Es voz Arabe». La segunda edición, no obstante, curiosamente se muestra más cauta: «Parece voz árabe». No es hasta el DRAE-1884 cuando se establece una etimología concreta - «Del ár. [...] alcharfa, la barredera»-, que se mantiene hasta 2001, fecha en que se prefiere la hipótesis «Quizá del ár. hisp. *aljárifa» (no avalada por el DCECH, pero sí por Corriente 1999: 197). Sorprendentemente escasa es de nuevo la información proporcionada sobre el uso de este tecnicismo local arcaico: únicamente la tercera persona verbal empleada en la definición de las ediciones dieciochescas - «que tambien llaman copo»- alude vagamente a la pertenencia de este término a un sector específico de hablantes, mientras que todas las ediciones posteriores -incluido el DRAE-2001 y el diccionario manual- omiten cualquier marcación.

2.6. Los redactores del $D A$ encontraron en las $O S e$. un término aluentola que reprodujeron erróneamente como albéndola en su obra, forma que se propagó posteriormente a otros diccionarios, como el de Terreros y otros más modernos, a pesar de que ya los autores de la segunda edición advirtieron el desliz estableciendo como lema albéntola. La autenticidad de esta última forma viene avalada no sólo por el hecho de aparecer cinco veces en la fuente, sino también por algunos registros lexicográficos independientes de diccionarios especializados más modernos que recoge el $D H$. Continúa en la nomenclatura académica -incluida la del diccionario manual- hasta la edición actualmente vigente.

10 La segunda edición del $D A$ únicamente regulariza la redacción de la definición suprimiendo las palabras introductorias «Es una...». 
También la definición se ha mantenido muy constante, al menos desde que en la segunda edición del $D A$ se redujera a la mitad el enunciado originario: «Espécie de red de hilo mui delgado para pescar peces mui pequeños, como son camarónes, pejes Reyes, y otros de semejante tamaño» mediante eliminación de la ejemplificación. ${ }^{11}$ La traducción latina igualmente sufrió una modificación (poco justificada) en 1780, cuando se suprimió de «piscibus minusculis capiendis reticulum» el adjetivo minusculis. En lo que hace a la etimología, todas las ediciones que contienen información de este tipo (y también el $D C E C H$ ) aceptan la propuesta en el $D A$. En ninguna, en cambio, se restringe el uso, ni diacrónica, ni diatópica ni diatécnicamente.

2.7. La autenticidad de la forma aljerife es segura, a juzgar tanto por la información fidedigna de Sáñez Reguart (quien atestigua una forma oral aherife) ${ }^{12}$ como por su existencia paralela en gallego-portugués. La voz está presente en todas las ediciones del diccionario académico, $\mathrm{y}$, a diferencia de las demás estudiadas aquí, se define con creciente precisión: si en el $D A-1726$ se describía todavía, de forma vaga, «red para pescar», en el $D A-1770$ se puntualiza «red muy grande para pescar», y, más de dos siglos después, en el $D R A E$-1992, se concreta: «red muy grande usada para pescar en las riberas de los ríos». La etimología propuesta por el $D A$, «Es voz tomada del árabe algarif, que vale esto mismo», es relevada en el DRAE-1884 por «Del ár. [...] alcharif, barredero», y en el DRAE-1899 por «Del ár. [...], el que barre», y, finalmente, en 2001, por «Quizá del ár. hisp. *aljárifa» (etimología que discrepa de la considerada posible en el $D C E C H$ ). Son curiosas las vacilaciones que sufren las marcas de uso: hasta el DRAE-1984 -o incluso hasta el DMILE-1989, si tomamos en consideración también el diccionario manual- la voz se restringía cronológicamente (hasta 1869 con una marca explícita, desde el $D R A E$-1884 ya sólo implícitamente dentro del enunciado definicional: «que se usaba antiguamente»). Desde el $D R A E-1992$, en cambio, el usuario no halla ya advertencia alguna acerca del uso limitado.

2.8. Por último, el derivado de la voz anterior aljerifero, documentado con el significado 'pescador de aljerife' exclusivamente en las OSe. (a juzgar por la documentación que ofrece el $D H$ ), figura en el diccionario académico -incluida la versión manual- desde el $D A$ hasta hoy. La definición se ha modificado en cinco ocasiones: la primera edición del $D A$ formula «el Pescador que pescába con la espécie de red llamada Algerífe»; la segunda abrevia «el pescador que pescaba con algerife»; en el DRAE1884 se prefiere «el que tenía por oficio pescar con aljerife»; y, finalmente, desde el

11 Tan sólo se introduciría y suprimiría varias veces la coma tras delgado.

12 También el CORDE contiene una documentación castellana, procedente de la anónima traducción de la Biblia Reina-Valera, de 1909. 
DRAE-1992 se define 'pescador de aljerife'. La demasiado amplia traducción latina «piscator» del $D A-1726$, en cambio, es respetada en las posteriores ediciones. El arcaísmo de la voz se señalaba a través del uso del imperfecto en la definición hasta DRAE-1984; del artículo correspondiente de las dos ediciones más recientes, en cambio, no se desprende ya limitación alguna del uso.

\section{Conclusiones}

De las ocho formas registradas por el $D A$ a partir de las $O S e$. tres son fantasmas lexicográficos originados a partir de erratas en la propia fuente-almacaero, alcabala y aljarfe-; una cuarta debe su carácter «fantasmagórico» a un desliz de los lexicógrafos al reproducir el dato en el diccionario -albéndola, en lugar de albéntola-. Almatrero y aljerifero son hápax, y almancebe y aljarfa términos que, si bien aparecen más de una vez en el texto sevillano, no han podido ser atestiguados -a juzgar por la documentación léxica reunida en los repertorios que he podido consultar- en fuente independiente. Las demás formas aquí estudiadas, aun cuando su existencia viene confirmada por fuentes posteriores, están sometidas a severas restricciones de uso: se trata sin excepción de tecnicismos arcaicos de difusión geográfica muy limitada.

El estudio de la presencia en el diccionario académico de esta corta serie de términos técnicos arcaicos del lenguaje de los pescadores sevillanos pone de relieve que la actitud general a la hora de editar una versión nueva ha sido la de reproducir mecánicamente la información contenida en la anterior, a lo sumo con algún retoque estilístico. Los cambios se introdujeron casi todos en las mismas pocas versiones. Así, en la segunda edición del $D A$ se modificaron sustancialmente la mitad de las definiciones (tanto españolas como latinas), sin duda tras un proceso de reevaluación de la fuente. En el $D R A E-1884$ se corrigieron tres de las definiciones y se ofrecieron etimologías nuevas en la mitad de los casos; ${ }^{13}$ el punto de partida fueron, no cabe duda, las investigaciones sobre el léxico de origen árabe que florecían en la época logrando brillantes resultados en los terrenos del acopio de documentación y del estudio etimológico. Un paso decisivo se da en el DRAE-1992, cuando, además de reformularse una de las definiciones, se suprimen tres entradas. Estas supresiones fueron un claro acierto, pues se trataba de formas cuando no inexistentes al menos de escasísimo uso real, formas cuyo registro lexicográfico no tiene justificación sino en un diccionario histórico o etimológico. No obstante, para aplicar este criterio de modo sistemático debería eliminarse también la entrada aljarfe (o quizá incluso la totalidad

13 Lo observado aquí viene a confirmar, pues, plenamente el juicio de Álvarez de Miranda (2000: 54-55) sobre la importancia del DRAE-1884. 
de las formas aquí estudiadas). En el $D R A E-2001$, finalmente, se han modificado tres de las etimologías (vid. ANEJo).

Podemos concluir que las tres reformas de más calado $(D A-1770, D R A E-1884$ y $D R A E$-1992) redundaron muy positivamente en el diccionario académico. En lo que se refiere a la más reciente, sin embargo, no puede negarse su carácter un tanto insuficiente o al menos tardío, pues los avances de la investigación lexicológica (especialmente la publicación del $D H$ o del $D C E C H$ ) podrían haberse aprovechado en mayor medida hace décadas. El aspecto más criticable es claramente la en exceso parca descripción del uso: a pesar de que se trata de voces de uso rarísimo (la mayoría hápax o al menos palabras limitadas a un solo texto, o incluso del todo inexistentes), no se advierte de la limitación diatécnica y diatópica más que esporádicamente y de modo implícito. La única restricción que se señala con frecuencia es la cronológica (aunque tampoco este aspecto se trata de forma sistemática, e incluso hemos observado algunos casos en que las marcas han sufrido una erosión creciente). Queda manifiesto, sin embargo, el enorme mérito del $D A$, que, fruto de un enorme esfuerzo y una seriedad científica asombrosa, ofrecía con gran originalidad, en una época en que la investigación histórica del léxico era prácticamente inexistente, un material léxico de sorprendente riqueza, material que, gracias a una intensa labor de interpretación lingüística y filológica, se logró describir con bastante exactitud; además, al reproducir en forma de autoridades el contexto del que se había extraído el léxico, se permitía a los usuarios evaluar en caso de duda la interpretación ofrecida. Al suprimirse en 1780 este aparato documental y repetirse generalmente de forma mecánica y acrítica el inicial cúmulo de materiales, ${ }^{14}$ la obra no se ha mantenido a la altura de lo que podía exigirse en vista del estado de la investigación lexicológica, y también del prestigio de que goza la obra académica.

Naturalmente, las pocas muestras aquí analizadas no permiten ninguna conclusión definitiva, por ejemplo en lo referente a una periodización de las ediciones del diccionario académico. Para ello serán necesarios numerosos estudios sistemáticos similares al que aquí he presentado.

${ }^{14} C f$. Álvarez de Miranda (2000: 50-51) y Ruhstaller (2000: 218). 


\begin{tabular}{|c|c|c|c|c|c|c|c|c|c|c|}
\hline 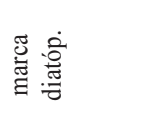 & $\begin{array}{l}\overrightarrow{0} \\
\text { ते } \\
\text { dे } \\
\text { I }\end{array}$ & ' & ' & 1 & ' & & & 1 & & ' \\
\hline 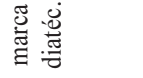 & 1 & ' & ' & ' & ' & & & ' & & ' \\
\hline 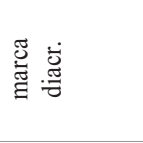 & 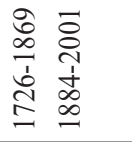 & $\begin{array}{l}+ \\
\infty \\
\infty \\
0\end{array}$ & 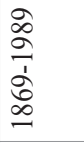 & 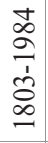 & ' & & & ' & 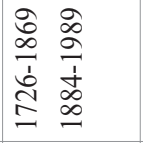 & 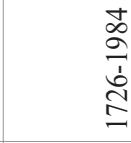 \\
\hline 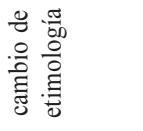 & $\begin{array}{l}+\infty \\
\infty \\
\infty\end{array}$ & & ' & $\begin{array}{l}+ \\
\infty \\
\infty\end{array}$ & 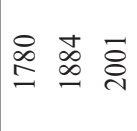 & & & & & \\
\hline 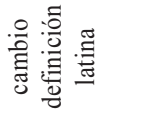 & & $\begin{array}{l}\tilde{\omega} \\
\infty \\
-\end{array}$ & $\stackrel{-}{\infty}$ & $\stackrel{ }{\stackrel{2}{I}}$ & 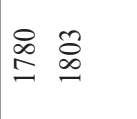 & & & 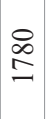 & & \\
\hline 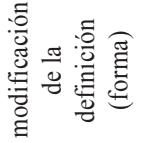 & ఠ্ণ & $\stackrel{?}{I}$ & $\begin{array}{l}\hat{\infty} \\
\infty\end{array}$ & $\begin{array}{l}\Phi \\
\infty \\
\infty\end{array}$ & $\begin{array}{l} \pm \\
\infty \\
\infty\end{array}$ & & & & & 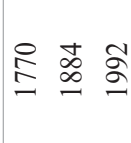 \\
\hline 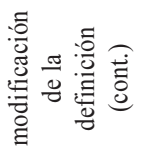 & 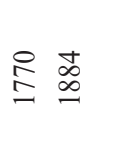 & $\begin{array}{l}+ \\
\infty \\
\infty\end{array}$ & 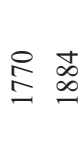 & $\stackrel{尺}{I}$ & $\begin{array}{l}\infty \\
\infty\end{array}$ & & & $\stackrel{?}{\stackrel{2}{I}}$ & 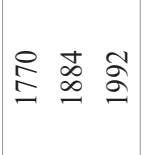 & \\
\hline 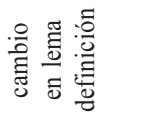 & & & & & & $\begin{array}{ll} & \overline{8} \\
\infty & 0\end{array}$ & & & & \\
\hline 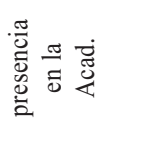 & 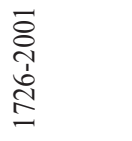 & $\begin{array}{l}2 \\
2 \\
2 \\
\vdots \\
\stackrel{1}{1} \\
\text { I }\end{array}$ & 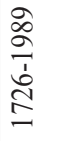 & 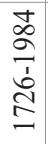 & $\begin{array}{l}\bar{\Xi} \\
\stackrel{1}{1} \\
\text { d } \\
\text { I }\end{array}$ & 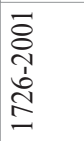 & $\stackrel{0}{\stackrel{N}{=}}$ & 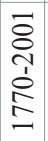 & $\begin{array}{l}\widetilde{\Xi} \\
\stackrel{1}{1} \\
\stackrel{1}{1} \\
\text { I }\end{array}$ & 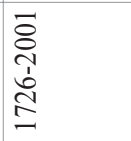 \\
\hline $\begin{array}{l}\text { ฮี } \\
\frac{0}{0} \\
\frac{0}{\infty}\end{array}$ & $*$ & $*$ & * & $*$ & & * & & & & $*$ \\
\hline 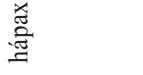 & & $*$ & $*$ & $*$ & & $*$ & & & & \\
\hline \multirow[t]{2}{*}{ 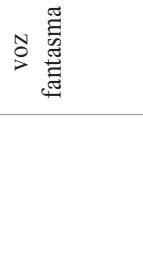 } & & & * & $*$ & & $*$ & $*$ & & & \\
\hline & 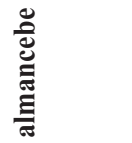 & 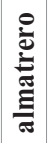 & 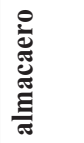 & 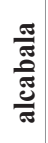 & $\frac{\pi}{\stackrel{\pi}{\frac{\pi}{\pi}}}$ & 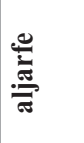 & 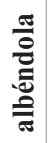 & 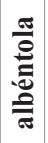 & 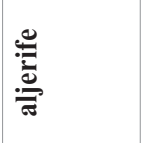 & \\
\hline
\end{tabular}




\section{REFERENCIAS BIBLIOGRÁFICAS}

Álvarez de Miranda, Pedro (2000a): «La lexicografía académica de los siglos XVIII y XIX», en I. Ahumada, ed., Cinco siglos de lexicografia del español (IV Seminario de Lexicografia hispánica, Jaén, 17 al 19 de noviembre de 1999), Jaén, Universidad de Jaén, pp. 35-61.

- (2000b): «Palabras y acepciones fantasma en los diccionarios académicos», en J.-C. Chevalier y M.-F. Delport, eds., La fabrique des mots. La néologie ibérique, París, Université de Paris-Sorbonne, pp. 55-73.

Azorín, Dolores (2000): Los diccionarios del español en su perspectiva histórica, Alicante, Universidad de Alicante.

Corriente, Federico (1999): Diccionario de los arabismos y voces afines en iberorromance, Madrid, Gredos.

DA. Real Academia Española (1726-1739): Diccionario de la lengua castellana, en que se explica el verdadero sentido de las voces, su naturaleza y calidad, con las phrases o modos de hablar, los proverbios o refranes, y otras cosas convenientes al uso de la lengua, Madrid [ed. facsímil, Madrid, 1964].

DA-1770. Real Academia Española (1770): Diccionario de la lengua castellana compuesto por la Real Academia Española. Segunda impresión corregida y aumentada, Madrid, Joachin Ibarra.

DCECH. Corominas, Joan y José Antonio Pascual (1980-1991): Diccionario crítico etimológico castellano e hispánico, Madrid, Gredos.

DH. Real Academia Española (1960-): Diccionario histórico de la lengua española, Madrid, EspasaCalpe.

DMILE-1989. Real Academia Española (1989): Diccionario manual e ilustrado de la lengua española, Madrid, Espasa-Calpe.

DRAE-1791. Real Academia Española $\left(1791^{3}\right)$ : Diccionario de la lengua castellana, Madrid, Viuda de Joaquín Ibarra.

DRAE-1803. Real Academia Española (18034): Diccionario de la lengua castellana, Madrid, Viuda de Ibarra.

DRAE-1817. Real Academia Española $\left(1817^{5}\right)$ : Diccionario de la lengua castellana, Madrid, Imprenta Real.

DRAE-1852. Real Academia Española $\left(1852^{10}\right)$ : Diccionario de la lengua castellana, Madrid, Imprenta Nacional.

DRAE-1869. Real Academia Española (1869 ${ }^{11}$ ): Diccionario de la lengua castellana, Madrid, Imprenta de don Manuel Rivadeneyra. 
DRAE-1884. Real Academia Española (1884 $\left.{ }^{12}\right)$ : Diccionario de la lengua castellana, Madrid, Imprenta de don Gregorio Hernando.

DRAE-1899. Real Academia Española (1899 $\left.{ }^{13}\right)$ : Diccionario de la lengua castellana, Madrid, Imprenta de los Sres. Hernando y Compañía.

DRAE-1984. Real ACAdemia Española (198420): Diccionario de la lengua española, Madrid, EspasaCalpe.

DRAE-1992. Real ACAdemia Española (1992²1): Diccionario de la lengua española, Madrid, EspasaCalpe.

DRAE-2001. Real Academia Española (200122): Diccionario de la lengua española, Madrid, EspasaCalpe.

García Cornejo, Rosalía (2001): «Los nombres de las redes en las «Ordenanzas de los cordoneros» (Sevilla, 24 de octubre de 1482)», Revista de Dialectología y tradiciones populares, LVI, pp. 217-244.

OSe. Ordenanzas de Sevilla: Recopilaçión de las ordenanças de la muy noble y muy leal cibdad de Seuilla: de todas las leyes y ordenamientos antiguos y modernos: cartas y prouisiones reales para la buena gouernaçion del bien publico y pacifico regimiento, Sevilla, 1527.

Ruhstaller, S. (2004): «Sobre la génesis del diccionario académico. Las Ordenanzas de Sevilla como fuente de material léxico en el Diccionario de Autoridades», Zeitschrift für romanische Philologie, 120/1, pp. 106-127.

- (2000): «Las autoridades del Diccionario de Autoridades», en S. Ruhstaller y J. Prado, eds., Tendencias en la investigación lexicográfica del español. El diccionario como objeto de estudio lingüístico y didáctico, Huelva, Universidad de Huelva, pp. 193-225. 